Journal of

Molecular Microbiology

and Biotechnology
J Mol Microbiol Biotechnol 2017;27:332-349

DOI: $10.1159 / 000484563$
Received: July 27, 2017

Accepted: October 17, 2017

Published online: December 7, 2017

\title{
Comparative Analyses of Transport Proteins Encoded within the Genomes of Bdellovibrio bacteriovorus HD100 and Bdellovibrio exovorus JSS
}

\author{
Fereshteh Heidari Tajabadi ${ }^{a}$ b Arturo Medrano-Soto $^{a}$ Masoud Ahmadzadeh ${ }^{b}$ \\ Gholamreza Salehi Jouzani ${ }^{c}$ Milton H. Saier Jr. ${ }^{a}$ \\ a Department of Molecular Biology, University of California at San Diego, La Jolla, CA, USA; ${ }^{b}$ Department of Plant \\ Protection, University of Tehran, Karaj, Iran; ' $D$ Department of Microbial Biotechnology, Agricultural Biotechnology \\ Research Institute of Iran (ABRII), Agricultural Research, Education and Extension Organization (AREEO), Karaj, Iran
}

\section{Keywords}

Predator · Bdellovibrio bacteriovorus · Bdellovibrio exovorus . Comparative genomics $\cdot$ Transport proteins

\begin{abstract}
Bdellovibrio, $\delta$-proteobacteria, including B. bacteriovorus (Bba) and B. exovorus (Bex), are obligate predators of other Gram-negative bacteria. While Bba grows in the periplasm of the prey cell, Bex grows externally. We have analyzed and compared the transport proteins of these 2 organisms based on the current contents of the Transporter Classification Database (TCDB; www.tcdb.org). Bba has 103 transporters more than Bex, $50 \%$ more secondary carriers, and 3 times as many MFS carriers. Bba has far more metabolite transporters than Bex as expected from its larger genome, but there are 2 times more carbohydrate uptake and drug efflux systems, and 3 times more lipid transporters. Bba also has polyamine and carboxylate transporters lacking in Bex. Bba has more than twice as many members of the Mot-Exb family of energizers, but both may have energizers for gliding motility. They use entirely different types of systems for iron acquisition. Both contain unexpectedly large numbers of pseudo-
\end{abstract}

() 2017 S. Karger AG, Basel genes and incomplete systems, suggesting that they are undergoing genome size reduction. Interestingly, all 5 outermembrane receptors in $\mathrm{Bba}$ are lacking in Bex. The 2 organisms have similar numbers and types of peptide and amino acid uptake systems as well as protein and carbohydrate secretion systems. The differences observed correlate with and may account, in part, for the different lifestyles of these 2 bacterial predators.

(c) 2017 S. Karger AG, Basel

\section{Introduction}

Bdellovibrios were discovered by Stolp and Petzhold in 1962 while attempting to isolate bacteriophage from soil samples. Bdellovibrio and like organisms (BALOs) are small, curved, highly motile, predatory, $\delta$-proteobacteria that prey on other Gram-negative bacteria. These predators are virtually ubiquitous, having been discovered in soil, compost, sewage, activated sludge, marine and terrestrial waters, and mammalian intestines [Jurkevitch, 2006; Rendulic et al., 2004]. Among them, B. bacteriovorus ( $\mathrm{Bba}$ ) has been the most studied of all BALOs. Bba is

\section{KARGER}

E-Mail karger@karger.com

www.karger.com $/ \mathrm{mmb}$
Milton H. Saier, Jr.

Department of Molecular Biology

University of California at San Diego

La Jolla, CA 92093-0116 (USA)

E-Mail msaier@ucsd.edu 
Table 1. Overview of the 2 Bdellovibrio species included in this study and their basic traits [Pasternak et al., 2013; Rendulic et al., 2004]

\begin{tabular}{|c|c|c|}
\hline Strain designation & Bba HD100 & Bex JSS \\
\hline Accession No. & NC_005363.1 & NC_020813.1 \\
\hline Genome size, $\mathrm{Mbp}$ & 3.78 & 2.66 \\
\hline Total proteins ${ }^{1}$ & 3,586 & 2,669 \\
\hline \multicolumn{3}{|l|}{ Total recognizable } \\
\hline transport proteins & 428 & 325 \\
\hline $\mathrm{GC} \%{ }^{2}$ & 50.6 & 46.1 \\
\hline Host location & Periplasmic & Epibiotic \\
\hline Prey range & Wide & Narrow \\
\hline
\end{tabular}

${ }^{1}$ In NCBI, total proteins are 3,534 and 2,618, respectively, in Bba and Bex.

${ }^{2}$ In NCBI, GC\% is 50.7 and 41.9, respectively, in Bba and Bex.

a periplasmic predator that enters through the outer membrane of the prey cell and metabolizes the "infected" cell from within [Lambert et al., 2015]. The life cycle of Bba consists of 2 phases: an attack phase and a periplasmic growth phase [Jurkevitch, 2006; Sockett, 2009]. During the attack phase, Bba swims rapidly, collides with its prey and attaches. The growth phase begins when Bba becomes irreversibly anchored on the prey cell surface before penetrating into the periplasmic space, where it grows, replicates, and eventually kills the prey cell. After forming an osmotically stable bdelloplast, and then after formation of a single long snake-like cell, Bba synchronously undergoes septation, generating multiple progeny cells, which lyse the bdelloplast envelope and escape [Barabote et al., 2007].

B. exovorus (Bex) is known to attack some Gram-negative bacteria using a different approach. Bex grows outside of the prey cell but utilizes the prey cell contents as nutrients. This epibiotic predator shares $93 \% 16 \mathrm{~S}$ rRNA gene sequence similarity with Bba. Bex was first isolated by Chanyi et al. [2013] from raw sewage, and based on molecular data and the different life cycles, Koval et al. [2013] proposed that this predator belongs to the Bdellovibrio genus. How it remains attached to the prey cell surface is not known, as membrane fusion does not occur between predator and prey. During epibiotic growth, instead of the long aseptate filament as observed for Bba, division occurs by binary fission [Chanyi et al., 2013].

In the single circular chromosome of Bba there are $3,782,950$ base pairs and 3,586 recognized protein genes. In Bex there are 2,657,893 base pairs and 2,669 protein genes. Table 1 presents the basic traits of these 2 strains.
As expected, there are more transmembrane transporter proteins in Bba than in Bex. Bba has potential protein secretory capabilities, at least 5 types of outer-membrane secretion systems, and 4 types of inner-membrane secretion systems [Barabote et al., 2007].

An analysis of the genomes of periplasmic predators, Bba and Bacteriovorax marinus, as well as epibiotic predators, Bex and Micavibrio aeruginosavorus, revealed that the genome sizes of these epibiotic predators are smaller, while the metabolic networks are well conserved. No core set of invasion-specific genes have been identified [Chanyi, 2014].

A genomic analysis of epibiotic and periplasmic predators by Pasternak et al. [2014] identified many different antibiotic resistance genes (most encoding efflux pumps) in different predators. Based in part on phylogenetic studies, they suggested that Bex evolved from a periplasmic predator by gene loss.

A detailed analysis [Barabote et al., 2007] revealed far more TonB/ExbBD-type and MotAB-type systems in Bba than in Escherichia coli. For survival, Bba must secrete hundreds of proteins to degrade the cytoplasmic contents of the prey, and then it must transport all of the degradation products back into its own periplasmic space before transporting them into the Bba cytoplasm. We found that the majority of the predicted transporters for this last process as well as for membrane export fall into the ATPbinding cassette $(\mathrm{ABC})$-type and major facilitator superfamily (MFS)-type permeases. The main goal of this study was to analyze how Bba and Bex differ in their transmembrane transport proteins with the hope that this comparative analysis will help explain their different behaviors.

\section{Materials and Methods}

At the time these studies were initiated (February 2016), the $\mathrm{Bba}$ and Bex genomes analyzed were the most complete and up to date versions available. The FASTA formatted protein-encoded sequences of each organism were used. Each protein sequence from the respective proteomes was queried and blasted against the Transporter Classification Database (TCDB; www.tcdb.org) using the program GBlast [Reddy and Saier, 2012]. GBlast retrieves the TC top hit sequence, TC number, protein size in numbers of amino acyl residues (aas), the numbers of predicted transmembrane a-helical spanners (TMSs) for both the query and hit proteins using the HMMTOP program, the E-value obtained when the query and hit proteins were compared, regions of sequence similarity, and regions of TMS overlap. The low complexity filter was not used because it is normally useful only for larger datasets, including proteins with multiple repeated elements. The web-based hydropathy, amphipathicity, and topology (WHAT) program was used with a window size of 19 residues and an angle of $100^{\circ}$ (as is 
appropriate for alpha helices) to display the hydropathy and amphipathicity plots for individual proteins [Zhai and Saier, 2001] in conjunction with TOPCONS for consensus prediction (TOPCONS, www.topcons.net) in order to resolve differences in the numbers of TMSs between the proteins retrieved and their TCDB homologs [Reddy and Saier, 2012]. The plots generated by WHAT allow the user to judge if a program such as HMMTOP has missed a TMS or has predicted a TMS inappropriately. A cut-off E value of 0.001 was used with the GBlast program to minimize false positives and proteins with unreliable degrees of sequence divergence, but all hits recorded were rigorously tested to determine homology, and they were examined in closer detail using the aforementioned steps. Low-scoring hits that proved to be recognizable transport proteins were incorporated into TCDB.

Proteins with no predicted TMSs were eliminated so that only integral membrane proteins, primarily multispanning membrane proteins, were retrieved. Proteins with only an N-terminal signal sequence are numerous, and the topological prediction programs often miss these. Consequently, the number of 0 or 1 TMS proteins retrieved was not reliable, and was therefore not always recorded. They were generally excluded from our analysis unless the hits were to TC entries in TC subclasses 1.B or 1.C. TMSs detected by GBlast are those of the $\alpha$-helical-type transporters, not of the $\beta$-porin types. Porins, known to consist of antiparallel transmembrane $\beta$-strands, are found primarily in TC subclass $1 . B$, while pore-forming toxins are in subclass 1.C, and they were further analyzed for $\beta$-strands using PRED-TMBB (http://bioinformatics. biol.uoa.gr/PRED-TMBB), which is capable of predicting transmembrane $\beta$-strands and the topology of $\beta$-barrel outer-membrane proteins of Gram-negative bacteria with 3 decoding methods (Vitebri, N-best, and Posterior Decoding) [Bagos et al., 2004]. Finally, to identify all constituents of multicomponent systems, and to deduce protein functions, we checked the genes and operons (www.biocyc.org), and then blasted each gene/protein against NCBI.

\section{Results}

Two Bdellovibrio genomes were analyzed for the occurrence of transport proteins using the TCDB [Saier et al., 2016] and the GBlast program [Reddy and Saier, 2012]. The detailed results are presented according to TC subclass in online supplementary Table 1 (see www. karger.com/doi/10.1159/000484563 for all online suppl. material).

\section{$\alpha$-Type Channels (TC Subclass 1.A)}

Channel proteins usually catalyze bidirectional movement of solutes by an energy-independent process by passage through a transmembrane aqueous pore or channel without evidence for a carrier-mediated mechanism. There is 1 member of the major intrinsic protein (MIP) family (TC 1.A.8) present in Bex but lacking in Bba. The MIP family is large and diverse, with proteins that func- tion in water, small neutral carbohydrates (e.g., glycerol), urea, $\mathrm{NH}_{3}, \mathrm{CO}_{2}, \mathrm{H}_{2} \mathrm{O}_{2}$, and ion transport by energy-independent mechanisms. The MIP-related gene in Bex is probably a pseudogene because the number of TMSs are fewer than normal with 2 missing N-terminal TMSs. Alternatively, its diminished size could be due to a sequencing error or an incorrect initiation codon assignment.

Bba has a channel-forming bestrophin homologue (TC 1.A.46) that Bex lacks. Characterized eukaryotic bestrophins are $\mathrm{Ca}^{2+}$-regulated homotetrameric anion channels found in animals, plants, and fungi. Prokaryotic homologues, distantly related to the eukaryotic proteins, were identified in many bacteria and a few archaea [Hagen et al., 2005]. They may function as chloride channels that may also serve as regulators of intracellular calcium signaling [Hartzell et al., 2008]. Ion selectivity has been examined for a bestrophin homologue from Klebsiella pneumoniae for which reversal of anion/cation selectivity and activation by mutations at the cytoplasmic exit region were demonstrated. The wild-type protein seems to be a cation $\left(\mathrm{Na}^{+}\right.$-selective) channel, but the I66F mutation changed it into an anion $\left(\mathrm{Cl}^{-}\right)$-selective channel [Yang et al., 2014]. There are 2 constrictions in the channel, 1 provides the ion selectivity while the other serves as the gate.

Both microorganisms possess 2 channels of the epithelial chloride channel family; TC 1.A.13. Genes encoding these proteins (BatA and BatB) are next to each other in a single operon with 7-8 genes; 2 of these genes encode an oxygen tolerance protein with a BatD domain (2 TMSs) and a magnesium chelatase domain; in Bex this last gene is in the adjacent operon. Interestingly, both Bat $\mathrm{A}$ and BatB contain magnesium chelatase domains. Of the 6 mechanosensitive channels found in each organism, 1 is of the MscL-type (TC 1.A.22) and 5 are of the MscStype (TC 1.A.23). There is poor similarity between $1 \mathrm{MscS}$ protein in Bba and Bex, suggesting that they are not orthologous. One $\mathrm{Mg}^{2+}$ transporter (TC 1.A.26), possibly a homodimer, has a homologue in each bacterium with the channel at the interface of the 2 subunits and a plug at the cytoplasmic face. The protein probably binds and transports $\mathrm{Mg}^{2+}, \mathrm{Mn}^{2+}$, and $\mathrm{Ca}^{2+}$ [Takeda et al., 2014]. In each organism, a single divalent metal ion channel belonging to the MIT or CorA family (TC 1.A.35) was identified.

In previous reports, $\mathrm{Bba}$ was shown to encode 3 MotA and 3 MotB homologues (TC 1.A.30); we also found 3 of each protein type (TC 3.A.30.1) but additionally identified 2 TolQ/TolR proteins as well as 4 sets of AglR/AglS/ $\mathrm{AglV}$ proteins. The latter 3 proteins presumably function in gliding motility but are homologues of MotA/ExbB, 
MotB/ExbD, and MotB/ExbD, respectively. Each pair of encoding genes related to MotA and MotB or TolQ and TolR are in a single operon. This is also true for the 4 sets of AglR, AglS, and AglV genes. Altogether, there are 9 different operons that contain these genes. Additionally, there is a single uncharacterized MotA homologue of 301 aas and 3-5 TMSs encoded at a distinct location, lacking a MotB homologue. The gene encoding this protein is flanked by genes that encode 2 large proteins, 1 annotated as a microtubule-binding protein but showing limited sequence similarity to TolA (522 aas; Q6MNS1), and the other a large Ala/Gly-rich protein (794 aas; Q6MNS3). In Bex we found a single pair of homologues of MotA and MotB, 2 homologues of TolQ and TolR, and 1 set of homologues of AlgR, AlgS, and AlgV. The genes of each system are close to each another in the same operon.

\section{Outer-Membrane Porins (TC 1.B)}

These proteins form transmembrane pores that usually allow the energy-independent passage of solutes across the outer membranes of these Gram-negative bacteria. The transmembrane portions of these proteins usually consist exclusively of $\beta$-strands which form a $\beta$-barrel [Reddy and Saier, 2016].

Bba has several $\beta$-structured porins that are not found in Bex. For example, 2 sugar porins (TC 1.B.3), 1 member of the Pseudomonas OprP porin (POP) family (TC 1.B.5), 2 nucleoside-specific channel-forming outer-membrane porins (Tsx; TC 1.B.10), 5 outer-membrane receptors (OMRs; TC 1.B.14), and 1 Omp50 porin (TC 1.B.60) are exclusively found in $\mathrm{Bba}$. One of the 2 sugar porin genes is close to the malFGK operon. The POP family gene is in an operon with genes encoding a ZnuABC zinc/manganese/iron uptake porter (TC 3.A.1.15). Tsx porins transport ribo- and deoxyribonucleosides as well as antibiotics such as abicidin. They also serve as receptors for bacteriophage and colicins in E. coli [Nieweg and Bremer, 1997]. Lastly, of the 5 OMRs in Bba, 4 are TonB-dependent transporters that bind and transport ferric chelates, while the other transports vitamin $\mathrm{B}_{12}$. OMR-mediated transport processes require energy in the form of a pmf and a complex of 3 inner-membrane proteins, TonB-ExbBExbD, to transduce this energy to the outer membrane [Noinaj et al., 2010].

Some $\beta$-structured porins in Bex are absent in Bba. These include a membrane fimbrial usher protein (TC 1.B.11), a putative bacterial porin (TC 1.B.62), and an OpcA-type outer-membrane porin (TC 1.B.65). This lastmentioned porin might play a role in adhesion to prey cells as Prince et al. [2002] reported for Neisseria meningitidis.
Finally, 1 putative $\beta$-barrel porin-2 (BBP2; TC 1.B.66) of unknown function was found in Bex but not Bba.

Fimbrial ushers are large proteins present in the outer membranes of Gram-negative bacteria [Dodson et al., 1993; Nuccio and Baumler, 2007; Van Rosmalen and Saier, 1993]. These ushers are responsible for the assembly and secretion of surface fimbriae and pili [Huang et al., 2009]. Gram-negative pathogens commonly exhibit adhesive pili on their surfaces that mediate attachment to the host [Remaut et al., 2008]. fimD is in an operon with a gene that could encode a pilus assembly protein like PapD.

Bba has an anion-selective OmpA-OmpF-type porin (TC 1.B.6) that may exist in 2 distinct conductance states [Arora et al., 2000; Nestorovich et al., 2006] and may function in the transport of many small molecules including phenylpropanoids (resveratrol, naringenin, and rutin) [Zhou et al., 2015]. The gene encoding this protein is in the same operon as one that encodes phosphoglycolate phosphatase. Bex has 2 sequence divergent OmpAOmpF-type porins (TC 1.B.6).

There are 7 outer-membrane factors (OMFs; TC 1.B.17) in Bba, and 5 in Bex, all of which function in conjunction with inner-membrane efflux pumps. The complexes formed allow the transport (export) of various solutes (heavy metal cations; drugs, oligosaccharides, proteins, etc.) across the 2 membranes of the Gram-negative bacterial cell envelope in a single energy-coupled step. One Bba homologue is not orthologous to any one of the proteins in Bex.

Four outer-membrane secretins (TC 1.B.22) were found in $\mathrm{Bba}$, and 3 were found in Bex. Secretins are large proteins that form homomultimeric ring structures with large central pores. They function in type II and III protein secretion, competence, fimbrial protein export (PilQ), phage assembly, and filamentous phage secretion [Linderoth et al., 1997; Martinez et al., 1998; McLaughlin et al., 2012; Nguyen et al., 2000]. PilQ forms a functional outer-membrane pore through which a pilus is extruded and retracted [Drake and Koomey, 1995].

$\mathrm{Bba}$ and Bex possess the outer-membrane protein insertion porin complex (TC 1.B.33), but NlpB and SmpA homologues are lacking. Two homologues of E. coli YaeT and 1 homologue of $E$. coli $\mathrm{YfiO}$ were identified in both bacteria. Also, there are 2 homologues of E. coli YfgL in $\mathrm{Bba}$ and 1 in Bex. Bba contains 2 more outer-membrane proteins (TC 1.B.33) than Bex. These 2 proteins are homologues of Omp85. Gram-negative bacterial outermembrane proteins are assembled from the periplasm into the outer membrane in processes that are usually, but 
not always, dependent on the BAM or OmpIP complex [Dunstan et al., 2015]. One of the yaeT genes in both microorganisms is flanked by genes involved in lipoprotein release (TC 3.A.1.125), LolC and LolD.

Each microorganism has an incomplete system of outer-membrane lipopolysaccharide export porins (LPS-EP, TC 1.B.42). There are just 4 constituents of a LPS export porin including LptD, LptB, LptG, and LptF. Both bacteria have 1 probable protein translocating porin (PorT, TC 1.B.44), 2 curli fiber subunit porins, CsgG (TC 1.B.48), 1 proteobacterial/verrucomicrobial porin (PVP, TC 1.B.71), 1 putative $\beta$-barrel porin, DUF481 (TC 1.B.75), and 1 outer-membrane lipoprotein insertion apparatus (LolA, TC 1.B.46). In Gram-negative bacteria, lipoproteins are transported to the outer membrane by the Lol system. In this process, lipoproteins are released from the inner membrane by the $\mathrm{ABC}$ transporter LolCDE and passed to LolA, a diffusible periplasmic molecular chaperone. Lipoproteins are then transferred to the OMR protein, LolB, for insertion into the outer membrane [McLeod et al., 2015]. In both bacteria, we found LolCDE (TC 3.A.1.125) as well as LolA, but we could not find LolB.

CsgAs are amyloid fiber proteins associated with biofilm formation, host cell adhesion, and invasion [Robinson et al., 2006]. Many organisms, from bacteria to humans, use the same fibrillar structure in order to perform a diverse range of biological functions. These functions include protection, aiding interface transitions, cell-cell recognition (e.g., chaplins, rodlins, and hydrophobins), epigenetic inheritance and memory [Pham et al., 2014]. As mentioned above, both microorganisms possess 2 proteins related to the curli fiber subunit porin, CsgG. The genes related to CsgG in Bex and Bba have different genomic contexts.

\section{Pore-Forming Toxins (TC 1.C)}

These proteins/peptides are synthesized by 1 cell and secreted for insertion into the membrane of another cell where they form transmembrane pores. They may exert their toxic effects by allowing the free flow of electrolytes and other small molecules across the membrane, or they may allow entry of a toxic protein into the target cell's cytoplasm.

Both microorganisms encode 4 putative toxins that show sequence similarity to established toxins belonging to 3 families. One is a pore-forming amphipathic helical peptide (TC 1.C.82), another is related to bacterial hemolysin A (HlyA; TC 1.C.109), and 2 are hemolysin III (Hly III; TC 1.C.113) transmembrane proteins.
Holins (TC 1.E)

Holins have a variety of proposed functions in prokaryotes and may play a role in cell lysis and biofilm formation [Reddy and Saier, 2013; Saier and Reddy, 2015]. We found 5 holins in Bba, 3 more than previously reported [Barabote et al., 2007]. Just 3 holins were found in Bex.

A single holin belonging to the CidA/LrgA family (TC 1.E.14) is present in Bba, but it is notably absent in Bex. The gene that encodes this protein is in the same operon as a murine hydrolase ( $\mathrm{LrgB} / \mathrm{CidB}$; TC 2.A.1.122). Upstream of the operon are 8 genes encoding hemABCLENGH. There is also a gene encoding a conserved 2-component sensor kinase/response regulator and a downstream gene encoding D-alanyl-D-alanine carboxypeptidase (a penicillin-binding protein). Both CidAB and $\operatorname{Lrg} \mathrm{AB}$ affect biofilm formation, oxidative stress, stationary phase survival, and antibiotic tolerance in a reciprocal fashion in other bacteria such as Staphylococcus aureus, and their genes can be regulated by a 2-component regulatory system, LytSR [Sharma-Kuinkel et al., 2009]. Three holins encoded in both Bex and Bba belong to the putative 3-4 TMS transglycosylase-associated holin family (TC 1.E.43). The gene related to 1 of the transglycosylase-associated holins in these 2 microorganisms is in the same operon as one that encodes an integral membrane protein of the rhomboid protease family (TC 9.B.104.2.1).

\section{Secondary Carriers (TC 2.A)}

Bba encodes 93 secondary carriers while Bex encodes 61 such proteins (TC subclass 2.A). Of the Bba proteins, 17 are members of the MFS (TC 2.A.1), while Bex only contains 6 . Five in Bba and 2 in Bex are probably drug exporters in the DHA1 family (TC 2.A.1.2). Three proteins in both BALOs belong to the following families: the fucose: $\mathrm{H}^{+}$symporter family (TC 2.A.1.7), the unknown major facilitator- 1 family (TC 2.A.1.24), and the peptideacetyl-coenzyme A transporter family (PAT; TC2.A.1.25).

Bba has some secondary carriers that Bex lacks, including 2 proteins in the organophosphate:Pi antiporter family (TC 2.A.1.4) that may function in sugar-phosphate uptake [Barabote et al., 2007]. Bba also has 1 protein in the metabolite: $\mathrm{H}^{+}$symporter family (TC 2.A.1.6) and 2 proteins in the acriflavin-sensitivity family (YnfM; TC 2.A.1.36) that are drug transporters, a single protein in the putative abietane diterpenoid transporter family (TC 2.A.1.30), and a member of the glycoside-pentosidehexuronide:cation symporter family (TC 2.A.2) that Bex lacks.

Both organisms possess 1 member of the amino acidpolyamine-organocation superfamily (APC; TC 2.A.3),
Heidari Tajabadi/Medrano-Soto/ Ahmadzadeh/Salehi Jouzani/Saier Jr. 
but these 2 proteins show low sequence similarity, implying that they are not orthologues. The protein in $\mathrm{Bba}$ is an amino acid transporter that belongs to the cationic amino acid transporter family (TC 2.A.3.3), while in Bex it belongs to the unknown APC-1 family (TC 2.A.3.14). The 2 bacteria have 1 protein each belonging to the cation diffusion facilitator (CDF) family (TC 2.A.4), members of which export heavy metal ions including cobalt, cadmium, and zinc, and possibly nickel, copper, and mercury. In $\mathrm{Bba}$, there is 1 more protein related to this family that probably functions as an $\mathrm{Mn}^{2+}$ efflux pump that Bex lacks. Both have a single member of the zinc $\left(\mathrm{Zn}^{2+}\right)$-iron $\left(\mathrm{Fe}^{2+}\right)$ permease (ZIP) family (TC 2.A.5) that most likely functions as a zinc uptake porter.

Although both BALOs possess similar types of proteins from subclass 2.A, the numbers of these proteins differ substantially. Bba encodes 10 proteins in the resistance-nodulation-cell division (RND; TC 2.A.6) family. Two are not found in Bex: a single putative lipid exporter belonging to the hydrophobe/amphiphile efflux-3 family (TC 2.A.6.7) and an acriflavin resistance protein (TC 2.A.6.3.3). The RND pumps secrete small molecules, most of which are antibacterial compounds and heavy metals, out of the cell, thus contributing to antibiotic and heavy metal resistance [Piddock, 2006]. Two of them in Bex seem to be pseudogenes.

Interestingly, Bex encodes 11 proteins related to the drug/metabolite transporter (DMT) superfamily (TC 2.A.7) although Bba encodes just 8. In Bex, 1 of the 2 homologues is a YedA transporter that probably exports amino acids and/or other metabolites [Zakataeva et al., 2006]; 1 is a putative riboflavin uptake porter, regulated by an FMN riboswitch [Vitreschak et al., 2002], another is likely to be a threonine/homoserine exporter, another is a quaternary ammonium compound-resistance protein, SugE, and still another is a chloramphenicol-sensitivity protein (TC 2.A.7.7.2) involved in antibiotic resistance [Carruthers et al., 2010]. In Bba, there is 1 small multidrug efflux pump and 1 threonine/homoserine exporter. Additional members of this superfamily are of unknown function. Among the members of this superfamily, 6 proteins in Bex and 1 in Bba are not closely related to other homologues in Bba or Bex, respectively.

In the monovalent cation:proton antiporter- 2 family (CPA2; TC 2.A.37), Bba has 5 related proteins while Bex has 2 , and in the chloride carrier/channel family (ClC; TC 2.A.49), Bba has 3 related proteins while Bex has 2. Interestingly, there is a complete transport system of the monovalent cation $\left(\mathrm{K}^{+}\right.$or $\left.\mathrm{Na}^{+}\right)$:proton antiporter-3 family (TC 2.A.63) in Bex, but in Bba, 2 components are missing

Genome Analysis of Bdellovibrio Species
(NhaB and NhaF). In Bex, the 7 genes that encode components of this system (A-G) are in the same operon, but in $\mathrm{Bba}$, they are not. The Bba system seems to be incomplete.

Each microorganism has a full TAT protein secretory system pathway, TatA-E (TC 2.A.64). Unlike the gene arrangement in $E$. coli, tat $A$ is not in an operon with tat $B$ and $t a t C$, but the distant location of tat $E$ is similar to that of $E$. coli. The TAT system exports large folded proteins containing characteristic twin-arginine motifs in their signal peptides. Together with TatB, TatC is part of a receptor/channel that directly interacts with Tat signal peptides [Cleon et al., 2015; Eimer et al., 2015; Kuzniatsova et al., 2016]. The twin-arginine transport systems in other bacteria transport folded metalloenzymes, and the Bba genome encodes 21 potential Tat-transported substrates [Chang et al., 2011].

The tatA2 (tatA) and tat $C$ gene products are essential for growth, despite the fact that they partially complement the corresponding mutations in E. coli where neither TatA nor TatC is essential for life. The essentiality of Bba TatA2 (TatA) is surprising given that the Bba genome encodes a second TatA homologue, TatA1 (TatE). Deletion of the tat $A 1$ gene causes a growth defect, despite the presence of its tatA2 homologue [Chang et al., 2011]; in Bex, the tat $A$ and tatE genes are in an operon with 5 genes encoding an oligopeptide transport system. In Bba, the tat $A$ and tat $E$ genes are far from each other, and tat $A$ is in an operon with a gene encoding a selenide:water dikinase, selenophosphate synthetase, which participates in selenocysteine biosynthesis.

Four members of the MOP superfamily (TC 2.A.66), from 3 different constituent families, were identified in $\mathrm{Bba}$. One is probably an MDR efflux pump of the MATE family (TC 2.A.66.1) of drug: $\mathrm{Na}^{+}$antiporters. The second is likely to be a polysaccharide exporter of the PST family (TC 2.A.66.2). The third and fourth belong to a mouse virulence family (TC 2.A.66.4) of putative flippases for lipids and peptidoglycan intermediates. These 2 proteins may flip a Lipid II peptidoglycan precursor from the cytoplasmic side of the inner membrane to the periplasmic side. One of the virulence factor genes in $\mathrm{Bba}$ is in an operon with 2 more genes encoding exonuclease $\mathrm{ABC}$ subunits $\mathrm{C}$ and $\mathrm{B}$. In Bex, 2 proteins belong to the MOP superfamily, a putative lipid and peptidoglycan intermediate flippase, and a polysaccharide exporter of the PST family. However, the 2 PST family members in Bba and Bex do not appear to be orthologues.

Two members of the autoinducer- 2 exporter family, AI-2E (TC 2.A.86), and 2 members of $\mathrm{Ca}^{2+}: \mathrm{H}^{+}$antiport- 
er-2 family, CaCA2 (TC 2.A.106), are in Bba while only 1 member of each exists in Bex. The members of the AI-2E family in $\mathrm{Bba}$ are purine regulon gene products under PurR control [Ravcheev et al., 2002], while the only member in Bex has low similarity with them and is probably an exporter of autoinducer-2. AI-2, a furanosyl borate diester, is a signaling molecule for interspecies communication in bacteria [Chen et al., 2002]. Bba encodes 3 members of the tellurium ion resistance family, TerC (TC 2.A.109), while Bex encodes 2 members of this family [Burian et al., 1998; Kormutakova et al., 2000].

Both microorganisms have 1 inner-membrane protein insertion protein, YidC (TC 2.A.9), involved in the insertion and folding of proteins in the bacterial cytoplasmic membrane. YidC can function both independently of and cooperatively with the general secretory pathways (Sec) machinery. As an independent insertase, YidC has been shown to insert Foc (subunit c of the F1F0 ATP synthase), MscL (a mechanosensitive channel), the phage M13 procoat protein, the Pf3 coat protein, and TssL, a tail-anchored membrane protein [Hennon et al., 2015]. It occupies the lateral gate of the SecYEG translocase and is displaced by the nascent membrane protein [Sachelaru et al., 2013]. YidC interacts with the ribosome at the ribosomal tunnel; a site for membrane protein insertion at the YidC proteinlipid interface has been identified [Wickles et al., 2014].

Both bacteria have 1 member of the neurotransmitter: sodium symporter family, NSS (TC 2.A.22), 1 member of the benzoate: $\mathrm{H}^{+}$symporter family, BenE (TC 2.A.46), 1 member of the phosphate: $\mathrm{Na}^{+}$symporter family, $\mathrm{PNaS}$ (TC 2.A.58), 2 members of the 4-toluene sulfonate uptake permease family (TC 2.A.102), 2 members of the bacterial murein precursor exporter family, MPE (TC 2.A.103), and a single member of the $\mathrm{Na}^{+} / \mathrm{H}^{+}$antiporter-E family (TC 2.A.111). The members of the NSS family catalyze uptake of a variety of neurotransmitters, amino acids, osmolytes, and related nitrogenous substances by a solute: $\mathrm{Na}^{+}$symport mechanism [Rudnick et al., 2014]. There are 2 proteins related to the MPE family, the RodA rod shape-determining protein and the FtsW cell division protein.

Bba has many additional secondary carriers that Bex lacks, including 1 proton-dependent oligopeptide transporter (TC 2.A.17), $1 \mathrm{Ca}^{2+}$ :cation antiporter (TC 2.A.19), 1 probable glutamate: $\mathrm{Na}^{+}$symporter (TC 2.A.27), $1 \mathrm{NhaC}$ $\mathrm{Na}^{+}: \mathrm{H}^{+}$antiporter (TC 2.A.35), 2 transporters (1 probably for 2-oxoglutarate) belonging to the divalent anion: $\mathrm{Na}^{+}$ symporter family (TC 2.A.47), a glycerol uptake system (TC 2.A.50), a chromate ion transporter (TC 2.A.51), a drug transporter, MtrF (TC 2.A.68), a $\mathrm{K}^{+}$uptake permease (TC 2.A.72), a short-chain fatty acid (SCFA) uptake system (TC 2.A.73), a ferroportin (TC 2.A.100), and a homologue of LrgB (TC 2.A.122) [Pick et al., 2013; Yang et al., 2012]. This latter has been reported to play a role in cell wall hydrolysis, possibly by regulating murein hydrolase export. A combination of the crystal structure and biochemical functional assays suggests that MtrF is an antibiotic efflux pump mediating bacterial resistance to sulfonamide antimetabolite drugs [Su et al., 2015]. Ferroportin is an iron-regulated transporter in mammals [Delaby et al., 2008]. Bba ferroportin is indeed a homologue of the human ferroportin, and mutations in some residues grossly affect its iron-binding and transport abilities [Bonaccorsi di Patti et al., 2015].

In Bex, there are 3 porters that are absent in Bba: a protein of the dicarboxylate/amino acid:cation $\left(\mathrm{Na}^{+} / \mathrm{H}^{+}\right)$ symporter family (TC 2.A.23), a protein of the vacuolar iron transporter family (TC 2.A.89), and an uptake transporter for biotin (vitamin $\mathrm{B}_{7}$, TC 2.A.88). The latter may function as an ECF transporter (TC 3.A.1.25) [Rodionov et al., 2009], and biotin, required by several carboxylases, plays a key role in $\mathrm{CO}_{2}$ fixation, for example, via the hydroxypropionate pathway [Cao et al., 2012; Fuchs, 2011]. The putative dicarboxylate transporter may transport orotate as a pyrimidine source [Baker et al., 1996].

\section{Ion-Gradient-Driven Energizers (TC 2.C)}

Energizers in subclass 2.C use the pmf across the cytoplasmic membrane, probably by allowing the electrophoretic transport of protons, and conveying conformational changes to outer-membrane pore-forming receptors [Zhai et al., 2003]. Homologous energizers also drive bacterial flagellar and gliding motility [Mignot and Nollmann, 2017]. The mechanisms are poorly understood, but these energizers undoubtedly couple proton $\left(\mathrm{H}^{+}\right)$or sodium $\left(\mathrm{Na}^{+}\right)$fluxes to the energized processes.

There are 4 homologues of TonB in Bba and 3 in Bex. Five proteins in Bba and 4 in Bex belong to the TolA energy-transducing system (TC 2.C.1.2.1, 4 constituents). The $\mathrm{H}^{+}$-channel-forming TolQ/R proteins are listed under TC 1.A.30.2.2. Proteins of this complex are TolA, TolB, YbgF, and Pal; they play a role in outer-membrane stabilization and probably in phospholipid transport [Shrivastava et al., 2017]. They are also required for the uptake of the group A colicins and the translocation of filamentous phage DNA into the cytoplasm of E. coli [Lazzaroni et al., 1999]. In both Bdellovibrios, we are missing 1 member (TolA), so it is possible that these proteins either can function with multiple cotranscribed pairs of TolQR proteins, or that these are not required [Barabote et al., 2007]. 
The ABC Superfamily (TC 3.A.1)

The ABC functional superfamily contains both uptake and efflux transport systems [Fatteh, 1978; Saurin et al., 1999] and includes at least 3 and maybe as many as 6 independently evolving families of channel-forming transmembrane constituents [Wang et al., 2009; Zheng et al., 2013 ]. Bba has 18 potential uptake systems and 20 potential efflux systems, while Bex has 14 potential uptake systems and 17 potential efflux systems. Thus, most of the $\mathrm{ABC}$ systems were retained during genome size reduction in Bex.

Seven ABC uptake systems in Bba are lacking in Bex. One is a maltose-type system (TC 3.A.1.1) with 2 membrane constituents, 1 of which is an R-M fusion protein. A second system, with 1 membrane constituent, is specific for polar amino acids (TC 3.A.1.3). This system may have 5 receptors encoded in different regions of the genome that probably have differing specificities. A third system is for the uptake of polyamines, especially putrescine and spermidine (TC 3.A.1.11). Three other uptake systems found only in Bba are specific for: (1) zinc and manganese (TC 3.A.1.15), (2) aromatic sulfonates, and (3) nitrate, respectively (TC 3.A.1.17). However, this last system has an NMT1/THI5 domain, and the substratebinding protein resembles a riboflavin system, so this system could be a riboflavin transporter [Anderson et al., 2016; Vitreschak et al., 2002]. A poorly characterized ABC-3-type efflux system (TC 3.A.1.137) may play a role in the export of antimicrobial peptides [Wang et al., 2009]. The 3 genes encoding this system are in an operon with genes encoding a universal stress protein, a phosphoribosyl transferase, and a short-chain alcohol dehydrogenase.

An ABC exporter with 2 constituents, found only in $\mathrm{Bba}$, belongs to the glycolipid flippase family (TC 3.A.1.142). An additional gene in the same operon encodes a sterol desaturase which functions in the biosynthesis of major sterols in eukaryotes. ATP-dependent flippases can drive the formation of membrane curvature by carrying out the net transfer of specific lipids from 1 leaflet of the membrane to the other [Graham and Kozlov, 2010]. The best-characterized bacterial lipid flippase in the $\mathrm{ABC}$ superfamily is MsbA, which is an essential protein in E. coli [Polissi and Georgopoulos, 1996]. This half-transporter operates as a homodimer in the cytoplasmic membrane. MsbA is required for trafficking of lipid A, a hexa-acylated glucosamine disaccharide intermediate in the assembly of LPS [Sharom, 2011]. Lipid A is biosynthesized on the inner face of the inner membrane, and MsbA translocates it to the outer leaflet [Doerrler et al.,
2004] and then to the outer membrane. Reconstitution studies using purified MsbA showed that it can flip a variety of glycerophospholipids in an ATP-dependent fashion [Eckford and Sharom, 2010].

GBlast of the Bba genome found both cell division proteins, FtsE and FtsX, belonging to the FtsX/FtsE septation family (TC 3.A.1.140); in Bex, just FtsE was initially found, but further study revealed a gene which encoded a protein of 250 aas and 4 TMSs that matches FtsX with just $24 \%$ identity to the Bba homologue. Strikingly, the genes in both bacteria are syntenic; in the same operon as the $f t s X$ gene in each BALO, there are 2 more genes that encode a peptidase and a protease.

There are 4 systems in Bex that are absent in Bba. First is a ferric iron uptake system ( 3 constituents, TC 3.A.1.10). We only found the receptor for this system in Bba. Second is an iron chelate uptake system (3 constituents, TC 3.A.1.14). Third is an L-histidine uptake system (3 constituents, TC 3.A.1.24), and finally is a glycerol phosphodiester uptake system (TC 3.A.1.20). The 3 genes encoding this system are in a single operon with a gene encoding a glycerophosphodiester phosphodiesterase, providing evidence that this transporter functions to take up such substrates.

The 2 BALOs have several similar ABC systems, including 1 for the uptake of nucleosides (TC 3.A.1.2), a system for the uptake of branched chain hydrophobic amino acids (LivJFGHM, TC 3.A.1.4.10), a phosphonate uptake system (PhnCDE, TC 3.A.1.9), an antimicrobial peptide resistance system (TC 3.A.1.136), an ethyl viologen exporter (TC 3.A.1.141), 3 systems for peptide uptake (TC 3.A.1.5), and 1 phosphate uptake system (TC 3.A.1.7). The 3 systems for peptide uptake are encoded in 3 different operons. In Bba, 1 of them contains an extra gene that encodes a soluble lytic murine transglycosylase, which suggests that the function of this system is uptake of degraded murine. Also, in Bex, 1 of these operons contains 2 genes related to TatA (the twin arginine targeting family). The phosphate uptake system may serve as both a transporter and a sensor for transcriptional repression of the pho regulon in the presence of external phosphate. The unphosphorylated EIIA ${ }^{\text {Ntr }}$ protein of the PTS in $E$. coli (TC 4.A) activates PhoR, the senor kinase that phosphorylates the response regulator, $\mathrm{PhoB}$, that activates the pho regulon [Luttmann et al., 2012].

In both bacteria, there is a system for the uptake of thiamin (TC 3.A.1.19). Four systems in Bba and 2 systems in Bex mediate organic solvent efflux (TC 3.A.1.27). Also in $\mathrm{Bba}$, there is an extra ATP-binding protein that is in an operon with a gene encoding a P-type ATPase, possibly 
specific for $\mathrm{Ca}^{2+}$ (TC 3.A.3.30.1). Both bacteria have a lipooligosaccharide export system (TC 3.A.1.102). One system in Bex and 2 systems in Bba are involved in drug export (TC 3.A.1.105). The system that exists in both bacteria has 2 constituents (YadGH), but the one that only exists in Bba has 5 (PltHIJKN) and probably functions as a multidrug exporter. Both bacteria have 2 single-component export systems, 1 for multiple drugs and the other for lipids (TC 3.A.1.106).

Both Bdellovibrio species possess a Uup protein (TC 3.A.1.120.6), an ATPase involved in DNA replication/repair with no recognized transport function [Carlier et al., 2012; Murat et al., 2008]. The gene related to this system in $\mathrm{Bba}$ is in the same operon as a gene that encodes a protein belonging to the MgtC family (9.B.20).

There are 4 lipoprotein translocases in $\mathrm{Bba}$ and $\mathrm{Bex}$ (TC 3.A.1.125) related to 2 different systems. In Bba, 1 of these operons contains 2 more genes encoding amino acid transporters. Both bacteria have export systems for macrolides and heavy metals, respectively. In both bacteria, there are 2 additional genes encoding a membrane fusion protein (MFP; TC 8.A.1.22) and an OMF (TC 1.B.17.2.6) in the same operons. Each permease plus these 2 proteins comprise a complete system for the export of molecules across both membranes of the Gram-negative bacterial cell envelope in a single energy-coupled step. In both organisms, the same operon encodes acyl hydrolases (lipases) and acyltransferases.

Both Bdellovibrios have a putative $\mathrm{ABC}$ exporter required for ratchet-type gliding motility (GldAFG, TC 3.A.1.132), and these systems may function in the secretion of a macromolecule such as an exopolysaccharide [Agarwal et al., 1997; Hunnicutt et al., 2002; McBride and Zhu, 2013]. In the same operons are 3 more genes, 1 of which encodes a galactokinase. Perhaps GldAFG is a galactose-containing polysaccharide exporter. The second system is necessary for social motility, pilus assembly and pilus subunit (PilA) export ( 2 constituents, PilHI, TC 3.A.1.132). Mutants of Myxobacteria defective for orthologous genes show elevated sporulation rates and abnormal development [Wu et al., 1998]. Interestingly, there are 7 more genes in $\mathrm{Bba}$, including 2 genes related to this system and 11 more in Bex in the corresponding operons. In both, 6 genes are the same and encode carbamoylphosphate synthase, small subunit, aspartate carbamoyl transferase, a signal peptidase/serine peptidase, leader peptidase, and an alkyl phosphonate $\mathrm{ABC}$ transporter (TC 3.A.1.9). Bba and Bex both have 2 drug conjugate export systems (TC 3.A.1.208).

\section{Other P-P-Bond-Hydrolysis-Driven Transporters}

(TC 3.A)

A high-affinity potassium uptake P-type ATPase, $\mathrm{KdpABC}$ (TC 3.A.3.7) in Bex is possibly regulated at the transcriptional level by the direct interaction of the IIA $^{\mathrm{Ntr}}$ protein of the PTS with the sensor kinase/response regulator system, $\mathrm{KdpDE}$, as for other proteobacteria [Prell et al., 2012]. However, in Bba, there are just 2 fragments of KdpA. Consequently, this system is not likely to be active because the corresponding genes are pseudogenes. Alternatively, this observation could reflect sequencing errors. Each BALO has another PATPase (TC 3.A.3.27) encoded in an operon with 5 or 6 other genes, where 3 of them encode proteins of the cytochrome oxidase complex (e.g., cytochrome oxidase maturation protein, cytochrome $\mathrm{C}$ oxidase, and an ironsulfur cluster protein). The function of this ATPase is probably the insertion of copper into cytochrome oxidase [Gonzalez-Guerrero et al., 2010; Raimunda et al., 2013]. There are 2 and 3 more P-ATPases in Bex and $\mathrm{Bba}$, respectively, all of them encoded in separate operons. Two of them in Bba and Bex are likely to be involved in heavy metal export.

Both bacteria have complete $\mathrm{H}^{+}$- or $\mathrm{Na}^{+}$-translocating F-type ATPases (TC 3.A.2) with 9 constituent proteins. Each has 2 subunits related to the B subunit. The genes encoding 2 other subunits of this system (A and C) are in the same operon as 5 more genes including DNA gyrase subunits $\mathrm{A}$ and $\mathrm{B}$.

Both Bdellovibrios have complete Sec systems (11 components, TC 3.A.5, including SecYEG, SecA, SecDF, FtsY and Ffh, YajC, 4.5 S RNA, and FtsE). A biphasic pulling-pushing force may act on TMSs during translocon-mediated membrane integration of substrate proteins [Ismail et al., 2012]. Intermediate structures for the insertion of integral membrane proteins have been visualized [Bischoff et al., 2014].

Insertion of the single-span ( $\mathrm{N}$-terminus in, $\mathrm{C}$-terminus out) protein, RodZ, requires only SecYEG, SecA, and the pmf, but not SecB, SecDF, YidC, or FtsY for insertion [Rawat et al., 2015]. The combined effects of ribosome and peptide binding to SecYEG may allow cotranslational membrane insertion of successive transmembrane segments [Ge et al., 2014]. The yajC, $\sec D$, and $\sec F$ genes are in an operon with 2 genes encoding a signal-strand DNAspecific exonuclease and a putative succinoglycan biosynthesis regulator. The secE gene is in an operon with a gene encoding a transcriptional antitermination protein, and it is flanked by ribosomal elongation factor genes. The $\sec Y$ gene is in an operon with a gene encoding adenylate
Heidari Tajabadi/Medrano-Soto/ Ahmadzadeh/Salehi Jouzani/Saier Jr. 
kinase and several genes encoding ribosomal proteins (5 in Bba and 18 in Bex).

There is a complete flagellar protein export system (type III secretory pathway, TC 3.A.6) in both bacteria. Some IIISP family systems in Gram-negative bacteria allow secretion of cytoplasmically synthesized proteins across both membranes of the cell envelope [Saier, 2007]. They are often concerned with secretion of virulence factors in pathogenic Gram-negative bacteria and may transport fully or partially folded substrate proteins [Lee and Schneewind, 2002]. Infrequent ATP hydrolysis by the FliI/FliJ ring is sufficient for gate activation, allowing processive translocation of exported flagellar protein substrates for efficient flagellar assembly [Minamino et al., 2014]. In these 2 BALOs, the genes involved in this system are syntenic. fliL, fliM, fliN, fliO, fliP, fliQ, fliR, flhB, flh $A$, $f l h F$, and $f l e N$ are in a single operon next to the gene that encodes FliA (RNA polymerase sigma factor for stage 3 flagellar biosynthesis). The other genes related to this system (fliE, fliF, fliG, fliH, fliI, and fliJ) occur in a separate operon. In this Bba operon, there are 2 other genes encoding the flagellar hook-length control protein, FliK and a basal-body rod modification protein, FlgD. However, in Bex they are in an adjacent operon. In both Bdellovibrios, there is an $\mathrm{Na}^{+}$-transporting, $\mathrm{K}^{+}$-dependent pyrophosphatase (TC 3.A.10). Also, a cell division protein, FtsK (TC 3.A.12) of known topology [Berezuk et al. 2014], can be found in both.

$\mathrm{Bba}$ and Bex have protein constituents resembling those of 4 related types of outer-membrane protein secretion systems. First is a type II protein secretion system, the main terminal branch (MTB; TC 3.A.15), which is like the PulC-O, S system in K. pneumoniae (12 constituents). Second is a pilin secretion/fimbrial assembly system resembling the PilA-EQTU FimTU system of Pseudomonas aeruginosa (9 constitutes). Third is a Legionella-like secretion pathway (Lsp)/fimbrial assembly system, LspC$M$, required for the survival of and replication in host cells [De Buck et al., 2007; Hales and Shuman, 1999; Rossier et al., 2004]. Lastly is a leptospiral type II protein secretion system (Gsp)/fimbrial assembly system, PilD/GspCDEFGHIJKLM [Buyuktimkin and Saier, 2015]. The systems found in the 2 Bdellovibrios have at least 13 constituents each.

Six clusters of motility and flagellar synthesis genes were found together with 6 flagellin genes at 4 different loci [Rendulic et al., 2004]. In 1 of these loci, the 2 Bdellovibrios has 5 genes, pilB, pilT, pilC, pilS, and pilR, involved in social gliding motility [Lambert et al., 2011; $\mathrm{Wu}$ et al., 1997]. The pilA gene is in a separate operon with another gene, probably pilG. PilS (with 6 TMSs) hits TC 2.A.21.9 in TCDB, and PilR hits TC 3.A.23. Another locus in both bacteria has 8 genes, pilQ, pilP, pilO, pilN, pilM, pilD, pilI, and pilH in 2 operons. Homologues of PilQ are tabulated in TC 1.B.22, PilM in TC 3.A.11, PilD in TC 3.A.15, and PilHI in TC 3.A.1.132. In both bacteria, we found 2 PilT proteins that may utilize the pmf for type IV pilus retraction [Maier et al., 2004]. Based on the work of Evans et al. [2007], the Bba genome showed a complete set of genes potentially encoding type IV pili and an incomplete gene set for Flp pili. The data suggest that type IV pili play a critical role in Bdellovibrio predation.

\section{Oxidoreduction-Driven Transporters (TC 3.D)}

Both Bba and Bex have a complete NADH dehydrogenase system (NuoA-N, TC 3.D.1). The genes that encode subunits $\mathrm{A}, \mathrm{H}, \mathrm{J}, \mathrm{K}, \mathrm{L}, \mathrm{M}$, and $\mathrm{N}$ are together in an operon, and the genes encoding subunits $\mathrm{B}, \mathrm{C} / \mathrm{D}, \mathrm{E}, \mathrm{F}, \mathrm{G}$, and I are in another. NuoL, NuoM, and NuoN are all homologous to proton:sodium antiporters and may play roles in pumping protons [Sato et al., 2013].

Two cytochrome oxidases (TC 3.D.4) exist in both bacteria. One has 2 constituents, 1 of which is a 13-TMS fusion protein ( $\mathrm{CcoN}$ and $\mathrm{CcoO})$. The genes involved in this system are in an operon with 5 other genes that encode: (1) a cation-transporting P-type ATPase (TC 3.A.3), (2) a cytochrome oxidase maturation protein, (3) an ironsulfur-containing protein (5 TMSs), and (4 and 5) 2 hypothetical proteins that may be related to cytochrome $c$ oxidase. The second system has 4 constituents (subunits I, II, III, and IV). The genes related to this second system are in an operon with 3 additional genes encoding: (1) a polyprenyltransferase (a cytochrome oxidase assembly factor), protoheme IX farnesyltransferase, an uncharacterized protein, (2) SCO1/SenC/PrrC, possibly involved in the biogenesis of respiratory and photosynthetic systems, and finally (3) cytochrome c.

Additionally, a bacterial respiratory but anaerobic nitric oxide reductase (NorBC, 3.D.4.10) exists in Bba but not Bex. Although nitric oxide reduction is a highly exergonic reaction, NOR is not a proton pump; it derives its substrate protons from the periplasmic side of the membrane [Flock et al., 2008]. The 2 genes encoding the NOR system are in a single operon with 2 more genes that encode nitric oxide reductase, subunit $\mathrm{Q}$, and the nitric oxide reductase activation protein, subunit $\mathrm{D}$, (NorQ and NorD). A complete succinate dehydrogenase system (3 constitutes, TC 3.D.10) is encoded within a single operon in each BALO. 


\section{Transmembrane 2-Electron Transfer Carriers}

(TC 5.A)

There are 2 proteins related to the disulfide bond oxidoreductase D (DsbD) family (TC 5.A.1) in each Bdellovibrio species. They are transmembrane electron flow carriers. A multicomponent molybdopterin-containing oxidoreductase (TC 5.A.3) is probably a dimethyl sulfoxide (DMSO) oxidoreductase.

\section{Auxiliary Transport Proteins (TC 8.A)}

Bba and Bex each encodes MFPs (TC 8.A.1). One encoding gene is in an operon with 2 other genes that encode a macrolide $\mathrm{ABC}$ exporter. In Bba there are 4 proteins related to the stomatin family (TC 8.A.21) while in Bex there are 2. In Bba there are 4 proteins related to putative adenylate cyclase, CyaA (TC 8.A.85), while in Bex there are 2 .

\section{Recognized Transporters of Unknown Biochemical Mechanism (TC 9.A)}

Two proteins belong to the ferrous iron uptake family in both Bba and Bex, FeoA, and FeoB (TC 9.A.8). Ellermeier et al. [2006] identified an exporter, SdpAB, which expels a toxic peptide, SdpC from the cell cytoplasm of Bacillus subtilis. There are 4 uncharacterized proteins, just in Bba, that belong to the putative SdpC peptide antibiotic-like killing factor exporter (SdpAB) family (TC 9.A.31). Two of them are homologues of SdpB (YvaX) of 287 aas and 308 aas, respectively, both with 6 TMSs. Their genes are adjacent to each other but are transcribed divergently.

In Bba there are 2 and in Bex there are 4 members of the HlyC/CorC (HCC) family of putative transporters (TC 9.A.40). The gene encoding 1 of these proteins (annotated as a $\mathrm{Mg}^{2+}$ and $\mathrm{Co}^{2+}$ transporter) in $\mathrm{Bba}$ is in the same operon with genes encoding a divalent cation tolerance protein, an orotate phosphoribosyltransferase and a hydrolase.

There are 3 putative protein secretion proteins in both microorganisms comprising a putative tight adherence (pilus) biogenesis apparatus (TC 9.A.47, TadABC). NCBI BLAST searches with tadA hit type II/IV secretion system proteins. In the operon with the $t a d A$ and $t a d B$ genes is a gene encoding the protein precursor, WapA. Genes that encode pilus assembly and chemotaxis proteins flank the $\operatorname{tad} A$ and $\operatorname{tad} B$ genes.

\section{Putative Transport Proteins (TC 9.B)}

Uncharacterized putative transport proteins are grouped in this subclass and will either be classified in
TCDB when the transport function of a member becomes established, or will be eliminated from the TC classification system if the proposed transport function is disproven.

In both Bdellovibrios, there are many putative transport proteins. These include 2 proteins related to the DedA family (TC 9.B.27), 1 protein related to the acid resistance membrane protein (HdeD) family (TC 9.B.36), 1 putative $\mathrm{Zn}^{2+}$-dependent protease in the M50 peptidase family (TC 9.B.149 with 5 TMSs), and 2 proteins related to the integral membrane CAAX protease family (TC 9.B.1). In $\mathrm{Bba}$, the genes that encode these last 2 proteins are in different parts of the genome, and 1 of them is in an operon with a gene that encodes a soluble lytic murein transglycosylase. In Bex, however, the genes are next to each other in different operons. The proximity of these genes suggests a role in peptidoglycan degradation and uptake. Both microorganisms have 3 proteins related to the rhomboid protease family (TC 9.B.104). The primary function of rhomboids is to cleave integral membrane proteins, releasing signal peptides [Lazareno-Saez et al., 2011].

There are 2 cytochrome $\mathrm{c}$ biogenesis proteins, CcsBA in both Bex and Bba, which are members of the putative heme handling protein family (HHP; TC 9.B.14) [Lee et al., 2007]. One of them has 10 TMSs and the other has 4 . In each bacterium, the encoding genes are in the same operon and hit 2 different parts of a fusion protein in TCDB, CcsBA. They export and protect heme from oxidation, have a heme-binding site within the bilayer and probably function as a heme channel [Frawley and Kranz, 2009].

Two putative permease proteins (PmpA and $\mathrm{PmpB}$ ), related to the YedE/YeeE family (TC 9.B.102), exist in both bacteria. The encoding genes ( $p m p A$ and $p m p B)$ are located in an operon with 2 genes encoding a molybdopterin biosynthesis protein and a permease related to TC 2.A.102.4.11, PmpC. The $p m p A$ gene is adjacent to $p m p B$. These genes might function in sulfur or selenium metabolism [Lin et al., 2015]. Both bacteria have a phospho-Nacetylmuramoyl-pentapeptide transferase (TC 9.B.146). The genes encoding these proteins are in operons with murD encoding UDP-N-acetylmuramoyl alanine-D-glutamate ligases. In Bex, a fts $W$ gene, encoding a cell division protein (TC 2.A.103 with 10 TMSs) is in the same operon, but in $\mathrm{Bba}$, the $\mathrm{fts} W$ gene is in another operon. Interestingly, the murD gene is flanked by genes that encode cell division proteins ( $f t s Q$, fts $A$, and $f t s Z$ ) and UDP$\mathrm{N}$-acetylmuramyl pentapeptide synthase subunits (murF, murE, murG, and murC). 
Table 2. Comparison of transporters in Bba and Bex according to transporter type (TC subclass)

\begin{tabular}{|c|c|c|c|c|}
\hline \multirow[t]{2}{*}{ TC subclass and description } & \multicolumn{2}{|c|}{ Transporter protein } & \multicolumn{2}{|l|}{$\%$} \\
\hline & $\mathrm{Bba}$ & Bex & Bba & Bex \\
\hline 1.A, a-type channels & 33 & 19 & 7.6 & 5.8 \\
\hline 1.B, $\beta$-barrel porins & 40 & 28 & 9.2 & 8.5 \\
\hline 1.C, pore-forming toxins & 4 & 4 & 0.9 & 1.2 \\
\hline 1.E, holins & 4 & 3 & 0.9 & 0.9 \\
\hline 2.A, porters & 93 & 61 & 21.3 & 18.5 \\
\hline 2.C, ion-gradient-driven energizers & 9 & 7 & 2.1 & 2.1 \\
\hline 3.A, P-P-bond-hydrolysis-driven transporters & 157 & 132 & 36 & 40.1 \\
\hline 3.D, oxidoreduction-driven transporters & 32 & 27 & 7.3 & 8.2 \\
\hline 5.A, transmembrane 2 -electron transfer carriers & 4 & 4 & 0.9 & 1.2 \\
\hline 8.A, auxiliary transport proteins & 9 & 5 & 1.8 & 1.5 \\
\hline \multicolumn{5}{|l|}{ 9.A, recognized transporters of unknown } \\
\hline biochemical mechanism & 13 & 10 & 2.8 & 2.7 \\
\hline 9.B, putative transport proteins & 39 & 30 & 8.9 & 9.1 \\
\hline Total & 437 & 330 & 100 & 100 \\
\hline
\end{tabular}

Class 1, channels; Class 2, secondary carriers; Class 3, primary active transporters; Class 5, transmembrane electron flow carriers; Class 8, auxiliary transport proteins; Class 9, transporters or putative transporters of unknown mechanism of action.

\section{Discussion}

While Bba is a periplasmic predator, Bex is an extracellular predator. We have analyzed the transporters in part to determine which systems might confer upon Bba its ability to enter its prey and which might confer upon Bex its ability to digest its prey while it remains external to the outer membrane of the prey. Roughly $10 \%$ of the genes in prokaryotic genomes are predicted to encode transporters [Ren and Paulsen, 2007]. In both bacteria, $12 \%$ of the proteins encode recognizable transport proteins, corresponding to established entries in TCDB.

In most bacteria, $3-8 \%$ of all the transport proteins are channel-type transporters [Ren and Paulsen, 2005]. Both $\mathrm{Bba}$ and Bex have much large percentages of channel proteins: 18.8 and $16.4 \%$ of the total transport proteins, respectively (Table 2 ). These include both $\alpha$-type cytoplasmic membrane channels and $\beta$-type outer-membrane porins. Bba has 2 possible halide-transporting a-type channel proteins that are lacking in Bex, possible candidates for either entry into the prey periplasm or eventual lysis of the prey cell.

Both bacteria have an unusually large complement of transporters for monovalent cations (Table 3). Some of these are proton channels that promote the generation or utilization of electrochemical gradients ( $\mathrm{pmf}$ and sodium motive force $[\mathrm{smf}])$. Among them, Bba has more proton channels (the Mot-Exb family) than Bex. Thus, there are 10 recognized homologues of MotA and 9 of MotB in $\mathrm{Bba}$, but only 4 of each in Bex. Some of these homologues may function to energize gliding motility rather than flagellar rotation [Barabote et al., 2007], but several may energize the transport of iron complexes across an outer membrane or ensure outer-membrane stability [Llamas et al., 2000]. Alternatively, the dual occurrence of these transport protein pairs in Bba could suggest that they are used for transport during the 2 phases of their dimorphic life cycle; the motile free-swimming stage and the predatory stage in the periplasm of the prey. It is likely that many genes are expressed in only 1 , but not both, of these 2 stages. The use of the smf as a chemiosmotic form of energy may be useful in high-salt environments.

Bex has a glycerol phosphodiester uptake system lacking in Bba. The uptake and utilization of glycerophosphodiesters are possibly important for the nutrition of Bex.

Bba has a larger number of $\beta$-barrel porins than Bex. Many (e.g., OMRs) function for uptake, while others (e.g., OMFs) mediate efflux. Interestingly, no OMR was identified in Bex. There are $2 \mathrm{ABC}$ iron uptake systems in Bex and 1 iron secondary carrier (2.A.89), all absent in Bba. On the other hand, there are 4 iron receptors (1.B.14) and 1 ferroportin (2.A.100) in Bba that are lacking in Bex. 
Table 3. Comparison of the numbers of different types of transporters specific for different classes of substrates between Bba and Bex

\begin{tabular}{|c|c|c|c|c|c|}
\hline \multirow[t]{2}{*}{$\begin{array}{l}\text { Substrate } \\
\text { category }\end{array}$} & \multirow[t]{2}{*}{ Substrate subcategory } & \multicolumn{2}{|c|}{$\begin{array}{l}\text { Transporter proteins } \\
\text { (systems) }\end{array}$} & \multicolumn{2}{|l|}{$\%$} \\
\hline & & $\mathrm{Bba}$ & Bex & $\mathrm{Bba}$ & Bex \\
\hline \multirow[t]{15}{*}{ Organic } & Polyamines & $4(1)$ & 0 & 0.9 & 0 \\
\hline & Amino acids & $16(2)$ & $12(2)$ & 3.7 & 3.7 \\
\hline & Peptide & $18(6)$ & $16(4)$ & 4.2 & 4.9 \\
\hline & Carboxylates & 4 & 0 & 0.9 & 0 \\
\hline & Drugs & $35(9)$ & $21(7)$ & 8.2 & 6.5 \\
\hline & Nucleotides/nucleosides/nucleobase & $8(2)$ & $3(1)$ & 1.9 & 0.9 \\
\hline & Mono/oligosaccharides & $13(2)$ & $6(1)$ & 3.0 & 1.9 \\
\hline & Glycosides & 5 & 3 & 1.2 & 0.9 \\
\hline & Phosphate ester & 0 & $3(1)$ & 0 & 0.9 \\
\hline & Terpene & 1 & 0 & 0.2 & 0 \\
\hline & Sugar derivatives/polyol & 2 & 1 & 0.5 & 0.3 \\
\hline & Vitamins & $5(2)$ & $4(1)$ & 1.2 & 1.2 \\
\hline & Siderophores & 4 & $6(2)$ & 0.9 & 1.9 \\
\hline & Enzyme cofactors & 2 & 2 & 0.5 & 0.6 \\
\hline & Nonspecific & 10 & 11 & 2.3 & 3.4 \\
\hline \multirow[t]{5}{*}{ Inorganic } & Anions & $21(3)$ & $13(2)$ & 4.9 & 4.0 \\
\hline & Monovalent cations & $73(5)$ & $55(6)$ & 17.1 & 17 \\
\hline & Divalent cations & $18(5)$ & $14(4)$ & 4.0 & 4.0 \\
\hline & Electrons & $8(2)$ & $8(2)$ & 1.9 & 2.5 \\
\hline & Water & 0 & 1 & 0 & 0.3 \\
\hline \multirow{5}{*}{$\begin{array}{l}\text { Macro- } \\
\text { molecules }\end{array}$} & Polysaccharides & $11(3)$ & $11(3)$ & 2.6 & 3.4 \\
\hline & Lipoproteins & $6(1)$ & $5(1)$ & 1.2 & 1.5 \\
\hline & Proteins & $69(5)$ & $62(5)$ & 16.1 & 19.1 \\
\hline & Nucleic acid (DNA/RNA) & 1 & 1 & 0.2 & 0.3 \\
\hline & Lipids & $14(3)$ & $5(2)$ & 3.3 & 1.5 \\
\hline Unknown & & $80(7)$ & $62(4)$ & 18.7 & 19.1 \\
\hline Total & & 428 & 325 & 100 & 100 \\
\hline
\end{tabular}

Possibly, the low-affinity secondary iron carriers perform uptake functions inside the prey cell, where iron concentrations are relatively high. The $\mathrm{ABC}$ transporters in Bex may function to allow high-affinity uptake in bacteria that lack OMRs. Since Bex lacks OMRs, iron cannot be accumulated in its periplasm against a concentration gradient, but Bex does have high-affinity ABC uptake systems. In contrast, Bba has the reverse situation, with OMRs but no iron-specific ABC systems. High periplasmic iron concentrations in Bba may allow the uptake of iron via the lower-affinity secondary carriers. Note that this situation differs from that in E. coli [Do et al., 2017; Tang et al., 2015].

Despite the higher numbers of transporters in $\mathrm{Bba}$, the numbers of pore-forming toxins are the same. Bba and
Bex probably operate by attaching and effacing (A/E) mechanisms. This type of invasion includes utilizing a type III secretion system to inject effector proteins into host cells. HlyA was identified in both bacteria. Sublytic concentrations of HlyA and other pore-forming toxins can modulate host cell survival during the course of bacterial infection.

Both Bdellovibrio species have general protein secretory pathway (Sec-SRP) complexes and full TAT systems in their inner membranes, TatA-E. In the outer membrane of Bex, we found a fimbrial usher porin, which acts in the fimbrial assembly process, together with a periplasmic fimbrial chaperone protein [Waksman and Hultgren, 2009]. Both Bdellovibrios have the Oxa system, which can insert proteins into the cytoplasmic membrane depend- 
ently or independently of the Sec system [Tamang et al., 2009]. Both bacteria possess a secretin that forms multisubunit pores through which macromolecules can be transported, usually proteins (export) or DNA (import) [Assalkhou et al., 2007; Sinha et al., 2008]. Secretins function in type II protein secretion, type III protein secretion, competence, fimbrial protein export and assembly, phage assembly, and filamentous phage secretion [Linderoth et al., 1997; Martinez et al., 1998; McLaughlin et al., 2012; Nguyen et al., 2000].

Both bacteria have type I secretion systems (T1SS), which are tripartite $\mathrm{ABC}$ pumps. Both have a type II secretion system (MTB, TC 3.A.15; T2SS, GspCDEFGIJKM), but 2 of the usual constituents ( $\mathrm{GspH}$ and $\mathrm{L}$ ) are missing in both. These systems may nevertheless be functional. Finally, both bacteria appear to have complete type III secretion systems (T3SS).

Evans et al. [2007] demonstrated the presence of polar pili on Bba and showed that disruption of pilA abolished predation. Mahmoud and Koval [2010] showed that these fibers were in fact type IV pili, and that Bba, in a coculture containing anti-PilA antibody, was not able to prey. These results indicate that a direct interaction between type IV pili and the prey cell is required for successful predation. Chanyi and Koval [2014] suggested that the role of type IV pili in the life cycle of Bba is for the initial recognition of and attachment to a prey cell, and possibly also for movement within the matrix of a biofilm. It is noteworthy that Bex lacks such structures.

Bba has about twice as many carbohydrate and 3 times as many lipid transporters as Bex (Table 3 ). The putative lipid transporters may be essential for adaptation inside the host periplasm during predation. As noted in Table 3, Bba has greater numbers of transporters for anions than Bex. This is true for chloride, phosphate/pyrophosphate, sulfate, and chromate. In Bba there are more transporters for nucleotides/nucleosides/nucleobases. In contrast, there are few if any recognized transporters for carboxylates in Bex (Table 3). Bba also has more drug exporters and more amino acid transporters than Bex. This undoubtedly reflects its superior metabolic versatility, conferring the ability of Bba to grow under a wide range of environmental conditions. The differences observed presumably reflect the different lifestyles, host ranges, and metabolic potentials of these 2 evolutionarily divergent Bdellovibrios.

Both bacteria have the same percentage of transporters for vitamins. Bba has $2 \mathrm{ABC}$ transport systems for vitamin $B_{1}$ and $B_{2}$, and 1 OMR for vitamin $B_{12}$, while $B$ ex has 1 system for $B_{1}$, an ImpX porter for vitamin $B_{2}$ and an uptake transporter for biotin.

Genome Analysis of Bdellovibrio Species
Bba has 2 outer-membrane transporters for nucleosides (Tsx) lacking in Bex. Nucleosides cross the outer membrane by diffusion through nonspecific water-filled pores such as OmpC and OmpF, but at submicromolar concentrations Tsx is necessary for the efficient uptake of nucleosides by facilitated diffusion. Tsx of E. coli functions as a channel for all nucleosides and deoxynucleosides except cytidine and deoxycytidine [Munch-Petersen et al., 1979]. Also, in each BALO, there is a full ABC system in the inner membrane for the uptake of nucleosides. In Bba there are 3 extra transporters in the inner membrane (YicM and 2 YdiKs); YicM is probably a purine nucleoside exporter [Jensen et al., 2008], and the 2 YdiKs probably mediate the uptake of nucleobases.

$\mathrm{Bba}$ has a complete $\mathrm{ABC}$ polyamine uptake system, PotABCD, lacking in Bex. The investigation of polyamine function in bacteria has revealed that these molecules have a broad range of biological functions [Igarashi and Kashiwagi, 2010; Wortham et al., 2007]. Bdellovibrios that have penetrated into the periplasmic space of their prey are incapable of completing their growth cycle in a suspension of low cell density. The addition of polyamines to such suspensions allows normal growth of the Bdellovibrios [Varon et al., 1983]. Transport of polyamines is associated with cellular growth and proliferation and may alleviate stress resulting from an elevated external $\mathrm{pH}$.

There is a short-chain fatty acid (SCFA) transporter only in Bba. SCFAs serve as messengers between colonic bacteria and the host [Ganapathy et al., 2013]. Maybe SCFAs serve the same function in Bdellovibrios. Bba and Bex are resistant to a panoply of drug/toxic compounds. Bba has 39 and Bex has 21 proteins related to drug/toxic compound efflux. Among them in Bba and Bex, respectively, 20 and 12 proteins belong to 10 and $8 \mathrm{ABC}$ systems from 8 different $\mathrm{ABC}$ families. We found more drug $\mathrm{ABC}$ exporters than previously reported for Bba. Analysis of the MFS transporters in these bacteria revealed that the greatest proportion of these systems export drugs. These pumps may protect Bdellovibrios against efforts of the host cell to defend itself against bacterial predation using toxic chemicals [Barabote et al., 2007].

Regarding secondary carriers for sugars, Bba and Bex, but particularly Bex, seem to have a very limited repertoire of such systems relative to most other sequenced Gram-negative bacteria, such as E. coli and other enteric bacteria. Also, Bba has just $1 \mathrm{ABC}$ uptake transporter for maltose. These results suggest that sugars are not a primary source of nutrition for Bdellovibrios.

What transport capability differences account for or contribute to the differences of the predatory life styles of 
Bba and Bex? First, the 2 organisms utilize entirely different types of systems for iron acquisition. For example, Bba has 4 OMRs while Bex has none, but Bex has highaffinity ABC-type uptake systems that Bba lacks. Second, $\mathrm{Bba}$ has far greater capacity for nutrient acquisition than Bex, particularly for lipids, sugars, carboxylates, polyamines, nucleotides, nucleosides, and nucleobases. This feature may explain why Bba exhibits a broad host range while Bex is a narrow host range predator. Third, Bba has far more drug exporters, possibly accounting for its greater resilience to host-anti-predator activities. Fourth, Bba has the SdpC killer factor and its exporter which Bex lacks. SdpC may promote host cell death. Fifth, while Bba has a type IV polar pilus, essential for predation, Bex has an unrelated fimbrial system that might allow the external attachment of Bex to its prey.

These differences contrast with other types of transporters that are present in both BALOs. Both bacteria appear to have numerous and the same protein secretion systems, a feature that is undoubtedly essential for their predatory life styles. They also have the same proton- transporting electron flow carriers and similar numbers of mechanosensitive channel proteins for osmotic adaptation. It seems clear that Bex has selectively and differentially lost and retained transport systems while acquiring others. These differences undoubtedly contribute to their different types of predatory behaviors. Future experimentalists can utilize these observations to zero in on the distinctive characteristics of these 2 dissimilar BALOs.

\section{Acknowledgements}

We would like to thank Jimmy Do and Bora Buyuktimkin for assistance with the bioinformatic research reported, Sabrina Phan and Harry Zhou for assistance with manuscript preparation, and the NIH (GM077402) for financial support.

\section{Disclosure Statement}

The authors declare no conflicts of interest.

\section{References}

Agarwal S, Hunnicutt DW, McBride MJ: Cloning and characterization of the Flavobacterium johnsoniae (Cytophaga johnsonae) gliding motility gene, gldA. Proc Natl Acad Sci USA 1997:94:12139-12144.

Anderson LN, Koech PK, Plymale AE, Landorf EV, Konopka A, Collart FR, Lipton MS, Romine MF, Wright AT: Live cell discovery of microbial vitamin transport and enzyme-cofactor interactions. ACS Chem Biol 2016;11: 345-354.

Arora A, Rinehart D, Szabo G, Tamm LK: Refolded outer membrane protein a of Escherichia coli forms ion channels with two conductance states in planar lipid bilayers. J Biol Chem 2000;275:1594-1600.

Assalkhou R, Balasingham S, Collins RF, Frye SA, Davidsen T, Benam AV, Bjoras M, Derrick JP, Tonjum T: The outer membrane secretin PiLQ from Neisseria meningitidis binds DNA. Microbiology 2007;153:1593-1603.

Bagos PG, Liakopoulos TD, Spyropoulos IC, Hamodrakas SJ: PRED-TMBB: a web server for predicting the topology of $\beta$-barrel outer membrane proteins. Nucleic Acids Res 2004 32:W400-W404.

Baker KE, Ditullio KP, Neuhard J, Kelln RA: Utilization of orotate as a pyrimidine source by Salmonella typhimurium and Escherichia coli requires the dicarboxylate transport protein encoded by dctA. J Bacteriol 1996;178:7099_ 7105 .
Barabote RD, Rendulic S, Schuster SC, Saier MH Jr: Comprehensive analysis of transport proteins encoded within the genome of Bdellovibrio bacteriovorus. Genomics 2007;90:424446.

Berezuk AM, Goodyear M, Khursigara CM: Sitedirected fluorescence labeling reveals a revised $\mathrm{N}$-terminal membrane topology and functional periplasmic residues in the Escherichia coli cell division protein FtsK. J Biol Chem 2014;289:23287-23301.

Bonaccorsi di Patti MC, Polticelli F, Tortosa V, Furbetta PA, Musci G: A bacterial homologue of the human iron exporter ferroportin. FEBS Lett 2015;589:3829-3835.

Burian J, Tu N, Kl'ucar L, Guller L, Lloyd-Jones G, Stuchlik S, Fejdi P, Siekel P, Turna J: In vivo and in vitro cloning and phenotype characterization of tellurite resistance determinant conferred by plasmid pte 53 of a clinical isolate of Escherichia coli. Folia Microbiol (Praha) 1998;43:589-599.

Buyuktimkin B, Saier MH Jr: Comparative genomic analyses of transport proteins encoded within the genomes of Leptospira species. Microb Pathog 2015;88:52-64.

Cao L, Bryant DA, Schepmoes AA, Vogl K, Smith RD, Lipton MS, Callister SJ: Comparison of Chloroflexus aurantiacus strain J-10-fl proteomes of cells grown chemoheterotrophically and photoheterotrophically. Photosynth Res 2012;110:153-168.
Carlier L, Haase AS, Burgos Zepeda MY, Dassa E, Lequin O: Secondary structure and NMR resonance assignments of the C-terminal DNAbinding domain of Uup protein. Biomol NMR Assign 2012;6:197-200.

Chang CY, Hobley L, Till R, Capeness M, Kanna M, Burtt W, Jagtap P, Aizawa S, Sockett RE: The Bdellovibrio bacteriovorus twin-arginine transport system has roles in predatory and prey-independent growth. Microbiology 2011;157:3079-3093.

Chanyi RM: Cell Biology of the Entry of Bdellovibrio and Like Organisms. Electronic Thesis and Dissertation Repository. 2014. http://ir. lib.uwo.ca/etd/2285.

Chanyi RM, Koval SF: Role of type IV pili in predation by Bdellovibrio bacteriovorus. PLoS One 2014;9:e113404.

Chanyi RM, Ward C, Pechey A, Koval SF: To invade or not to invade: two approaches to a prokaryotic predatory life cycle. Can J Microbiol 2013;59:273-279.

Chen X, Schauder S, Potier N, Van Dorsselaer A, Pelczer I, Bassler BL, Hughson FM: Structural identification of a bacterial quorum-sensing signal containing boron. Nature 2002;415: 545-549.

Cleon F, Habersetzer J, Alcock F, Kneuper H, Stansfeld PJ, Basit H, Wallace MI, Berks BC, Palmer $\mathrm{T}$ : The TatC component of the twin-arginine protein translocase functions as an obligate oligomer. Mol Microbiol 2015;98:111-129. 
De Buck E, Anne J, Lammertyn E: The role of protein secretion systems in the virulence of the intracellular pathogen legionella pneumophila. Microbiology 2007;153:3948-3953.

Delaby C, Pilard N, Puy H, Canonne-Hergaux F: Sequential regulation of ferroportin expression after erythrophagocytosis in murine macrophages: early mRNA induction by haem, followed by iron-dependent protein expression. Biochem J 2008;411:123-131.

Do J, Zafar H, Saier MH Jr: Comparative genomics of transport proteins in probiotic and pathogenic Escherichia coli and Salmonella enterica strains. Microb Pathog 2017;107: 106-115.

Dodson KW, Jacob-Dubuisson F, Striker RT, Hultgren SJ: Outer-membrane PapC molecular usher discriminately recognizes periplasmic chaperone-pilus subunit complexes. Proc Natl Acad Sci USA 1993;90:3670-3674.

Doerrler WT, Gibbons HS, Raetz CR: MsbA-dependent translocation of lipids across the inner membrane of Escherichia coli. J Biol Chem 2004;279:45102-45109.

Drake SL, Koomey M: The product of the pilQ gene is essential for the biogenesis of type iv pili in Neisseria gonorrhoeae. Mol Microbiol 1995; 18:975-986.

Eckford PD, Sharom FJ: The reconstituted Escherichia coli MsbA protein displays lipid flippase activity. Biochem J 2010;429:195-203.

Eimer E, Frobel J, Blummel AS, Muller M: Tate as a regular constituent of bacterial twin-arginine protein translocases. J Biol Chem 2015; 290:29281-29289.

Ellermeier CD, Hobbs EC, Gonzalez-Pastor JE, Losick R: A three-protein signaling pathway governing immunity to a bacterial cannibalism toxin. Cell 2006;124:549-559.

Evans KJ, Lambert C, Sockett RE: Predation by Bdellovibrio bacteriovorus HD100 requires type IV pili. J Bacteriol 2007;189:4850-4859.

Fatteh A: Exhumation, autopsy, second autopsy. Leg Med Annu 1978;1978:151-163.

Flock U, Thorndycroft FH, Matorin AD, Richardson DJ, Watmough NJ, Adelroth P: Defining the proton entry point in the bacterial respiratory nitric-oxide reductase. J Biol Chem 2008; 283:3839-3845.

Frawley ER, Kranz RG: CcsBA is a cytochrome $c$ synthetase that also functions in heme transport. Proc Natl Acad Sci USA 2009;106: 10201-10206.

Fuchs G: Alternative pathways of carbon dioxide fixation: insights into the early evolution of life? Annu Rev Microbiol 2011;65:631-658.

Ganapathy V, Thangaraju M, Prasad PD, Martin PM, Singh N: Transporters and receptors for short-chain fatty acids as the molecular link between colonic bacteria and the host. Curr Opin Pharmacol 2013;13:869-874.

Ge Y, Draycheva A, Bornemann T, Rodnina MV, Wintermeyer W: Lateral opening of the bacterial translocon on ribosome binding and signal peptide insertion. Nat Commun 2014; 5:5263.
Gonzalez-Guerrero M, Raimunda D, Cheng X, Arguello JM: Distinct functional roles of homologous $\mathrm{Cu}+$ efflux ATPases in Pseudomonas aeruginosa. Mol Microbiol 2010;78:1246-1258.

Graham TR, Kozlov MM: Interplay of proteins and lipids in generating membrane curvature. Curr Opin Cell Biol 2010;22:430-436.

Hagen AR, Barabote RD, Saier MH: The bestrophin family of anion channels: identification of prokaryotic homologues. Mol Membr Biol 2005;22:291-302.

Hales LM, Shuman HA: Legionella pneumophila contains a type II general secretion pathway required for growth in amoebae as well as for secretion of the Msp protease. Infect Immun 1999;67:3662-3666.

Hartzell HC, Qu Z, Yu K, Xiao Q, Chien LT: Molecular physiology of bestrophins: multifunctional membrane proteins linked to best disease and other retinopathies. Physiol Rev 2008;88:639-672.

Hennon SW, Soman R, Zhu L, Dalbey RE: YidC/ Alb3/Oxa1 family of insertases. J Biol Chem 2015;290:14866-14874.

Huang Y, Smith BS, Chen LX, Baxter RH, Deisenhofer J: Insights into pilus assembly and secretion from the structure and functional characterization of usher PapC. Proc Natl Acad Sci USA 2009;106:7403-7407.

Hunnicutt DW, Kempf MJ, McBride MJ: Mutations in Flavobacterium johnsoniae gldF and gldG disrupt gliding motility and interfere with membrane localization of GldA. J Bacteriol 2002;184:2370-2378.

Igarashi K, Kashiwagi K: Modulation of cellular function by polyamines. Int J Biochem Cell Biol 2010;42:39-51.

Jensen KF, Dandanell G, Hove-Jensen B, WillemoEs M: Nucleotides, nucleosides, and nucleobases. EcoSal Plus 2008, DOI: 10.1128/ ecosalplus.3.6.2.

Jurkevitch E: Isolation and classification of Bdellovibrio and like organisms. Curr Protoc $\mathrm{Mi}$ crobiol 2006;7:B1.1-B1.17.

Kormutakova R, Klucar L, Turna J: DNA sequence analysis of the tellurite-resistance determinant from clinical strain of Escherichia coli and identification of essential genes. Biometals 2000;13:135-139.

Koval SF, Hynes SH, Flannagan RS, Pasternak Z, Davidov Y, Jurkevitch E: Bdellovibrio exovorus sp. Nov., a novel predator of Caulobacter crescentus. Int J Syst Evol Microbiol 2013;63: 146-151.

Kuzniatsova L, Winstone TM, Turner RJ: Identification of protein-protein interactions between the TatB and TatC subunits of the twinarginine translocase system and respiratory enzyme specific chaperones. Biochim Biophys Acta 2016;1858:767-775

Lambert C, Cadby IT, Till R, Bui NK, Lerner TR, Hughes WS, Lee DJ, Alderwick LJ, Vollmer W, Sockett RE, Lovering AL: Ankyrin-mediated self-protection during cell invasion by the bacterial predator Bdellovibrio bacteriovorus. Nat Commun 2015;6:8884.
Lambert C, Fenton AK, Hobley L, Sockett RE: Predatory Bdellovibrio bacteria use gliding motility to scout for prey on surfaces. J Bacteriol 2011;193:3139-3141.

Lazareno-Saez C, Brooks CL, Lemieux MJ: Structural comparison of substrate entry gate for rhomboid intramembrane peptidases. Biochem Cell Biol 2011;89:216-223.

Lazzaroni JC, Germon P, Ray MC, Vianney A: The Tol proteins of Escherichia coli and their involvement in the uptake of biomolecules and outer membrane stability. FEMS Microbiol Lett 1999;177:191-197.

Lee JH, Harvat EM, Stevens JM, Ferguson SJ, Saier MH Jr: Evolutionary origins of members of a superfamily of integral membrane cytochrome $c$ biogenesis proteins. Biochim Biophys Acta 2007;1768:2164-2181.

Lee VT, Schneewind O: Yop fusions to tightly folded protein domains and their effects on Yersinia enterocolitica type III secretion. J Bacteriol 2002;184:3740-3745

Lin J, Peng T, Jiang L, Ni JZ, Liu Q, Chen L, Zhang $\mathrm{Y}$ : Comparative genomics reveals new candidate genes involved in selenium metabolism in prokaryotes. Genome Biol Evol 2015;7: 664-676.

Linderoth NA, Simon MN, Russel M: The filamentous phage piv multimer visualized by scanning transmission electron microscopy. Science 1997;278:1635-1638.

Llamas MA, Ramos JL, Rodriguez-Herva JJ: Mutations in each of the tol genes of pseudomonas putida reveal that they are critical for maintenance of outer membrane stability. J Bacteriol 2000;182:4764-4772.

Luttmann D, Gopel Y, Gorke B: The phosphotransferase protein EIIA ${ }^{\mathrm{Ntr}}$ modulates the phosphate starvation response through interaction with histidine kinase phor in Escherichia coli. Mol Microbiol 2012;86:96-110.

Mahmoud KK, Koval SF: Characterization of type IV pili in the life cycle of the predator bacterium Bdellovibrio. Microbiology 2010;156: 1040-1051.

Maier B, Koomey M, Sheetz MP: A force-dependent switch reverses type IV pilus retraction. Proc Natl Acad Sci USA 2004;101:1096110966.

Martinez A, Ostrovsky P, Nunn DN: Identification of an additional member of the secretin superfamily of proteins in Pseudomonas aeruginosa that is able to function in type II protein secretion. Mol Microbiol 1998;28:1235-1246.

McBride MJ, Zhu Y: Gliding motility and Por secretion system genes are widespread among members of the phylum Bacteroidetes. J Bacteriol 2013;195:270-278.

McLaughlin LS, Haft RJ, Forest KT: Structural insights into the type II secretion nanomachine. Curr Opin Struct Biol 2012;22:208-216.

McLeod SM, Fleming PR, MacCormack K, McLaughlin RE, Whiteaker JD, Narita S, Mori M, Tokuda H, Miller AA: Small-molecule inhibitors of Gram-negative lipoprotein trafficking discovered by phenotypic screening. J Bacteriol 2015;197:1075-1082. 
Mignot T, Nollmann M: New insights into the function of a versatile class of membrane molecular motors from studies of Myxococcus xanthus surface (gliding) motility. Microb Cell 2017;4:98-100.

Minamino T, Morimoto YV, Kinoshita M, Aldridge PD, Namba K: The bacterial flagellar protein export apparatus processively transports flagellar proteins even with extremely infrequent ATP hydrolysis. Sci Rep 2014;4: 7579.

Munch-Petersen A, Mygind B, Nicolaisen A, Pihl NJ: Nucleoside transport in cells and membrane vesicles from Escherichia coli k12. J Biol Chem 1979;254:3730-3737.

Murat D, Goncalves L, Dassa E: Deletion of the Escherichia coli uup gene encoding a protein of the ATP binding cassette superfamily affects bacterial competitiveness. Res Microbiol 2008;159:671-677.

Nestorovich EM, Sugawara E, Nikaido H, Bezrukov SM: Pseudomonas aeruginosa porin OprF: properties of the channel. J Biol Chem 2006;281:16230-16237.

Nguyen L, Paulsen IT, Tchieu J, Hueck CJ, Saier MH Jr: Phylogenetic analyses of the constituents of type III protein secretion systems. J Mol Microbiol Biotechnol 2000;2:125-144.

Nieweg A, Bremer E: The nucleoside-specific Tsx channel from the outer membrane of salmonella typhimurium, Klebsiella pneumoniae and Enterobacter aerogenes: functional characterization and DNA sequence analysis of the tsx genes. Microbiology 1997;143(Pt 2): 603-615.

Noinaj N, Guillier M, Barnard TJ, Buchanan SK: TonB-dependent transporters: regulation, structure, and function. Annu Rev Microbiol 2010;64:43-60.

Nuccio SP, Baumler AJ: Evolution of the chaperone/usher assembly pathway: fimbrial classification goes greek. Microbiol Mol Biol Rev 2007;71:551-575.

Pasternak Z, Njagi M, Shani Y, Chanyi R, Rotem O, Lurie-Weinberger MN, Koval S, Pietrokovski S, Gophna U, Jurkevitch E: In and out: an analysis of epibiotic versus periplasmic bacterial predators. ISME J 2014;8:625-635.

Pasternak Z, Pietrokovski S, Rotem O, Gophna U, Lurie-Weinberger MN, Jurkevitch E: By their genes ye shall know them: genomic signatures of predatory bacteria. ISME J 2013;7:756-769.

Pham CL, Kwan AH, Sunde M: Functional amyloid: widespread in nature, diverse in purpose. Essays Biochem 2014;56:207-219.

Pick TR, Brautigam A, Schulz MA, Obata T, Fernie AR, Weber AP: PLGG1, a plastidic glycolate glycerate transporter, is required for photorespiration and defines a unique class of metabolite transporters. Proc Natl Acad Sci USA 2013;110:3185-3190.

Piddock LJ: Multidrug-resistance efflux pumps not just for resistance. Nat Rev Microbiol 2006;4:629-636.
Polissi A, Georgopoulos C: Mutational analysis and properties of the $m s b A$ gene of Escherichia coli, coding for an essential ABC family transporter. Mol Microbiol 1996;20:12211233.

Prell J, Mulley G, Haufe F, White JP, Williams A, Karunakaran R, Downie JA, Poole PS: The $\mathrm{PTS}^{\mathrm{Ntr}}$ system globally regulates ATP-dependent transporters in Rhizobium leguminosarum. Mol Microbiol 2012;84:117-129.

Prince SM, Achtman M, Derrick JP: Crystal structure of the OpcA integral membrane adhesin from Neisseria meningitides. Proc Natl Acad Sci USA 2002;99:3417-3421.

Raimunda D, Padilla-Benavides T, Vogt S, Boutigny S, Tomkinson KN, Finney LA, Arguello JM: Periplasmic response upon disruption of transmembrane $\mathrm{Cu}$ transport in Pseudomonas aeruginosa. Metallomics 2013;5: 144-151.

Ravcheev DA, Gel'fand MS, Mironov AA, Rakhmaninova $A B$ : Purine regulon of gammaproteobacteria: a detailed description (in Russian). Genetika 2002;38:1203-1214.

Rawat S, Zhu L, Lindner E, Dalbey RE, White SH: SecA drives transmembrane insertion of RodZ, an unusual single-span membrane protein. J Mol Biol 2015;427:1023-1037.

Reddy BL, Saier MH Jr: Properties and phylogeny of 76 families of bacterial and eukaryotic organellar outer membrane pore-forming proteins. PLoS One 2016;11:e0152733.

Reddy VS, Saier MH Jr: BioV suite - a collection of programs for the study of transport protein evolution. FEBS J 2012;279:2036-2046.

Remaut H, Tang C, Henderson NS, Pinkner JS, Wang T, Hultgren SJ, Thanassi DG, Waksman G, Li H: Fiber formation across the bacterial outer membrane by the chaperone/usher pathway. Cell 2008;133:640-652.

Ren Q, Paulsen IT: Comparative analyses of fundamental differences in membrane transport capabilities in prokaryotes and eukaryotes. PLoS Comput Biol 2005; 1:e27.

Ren Q, Paulsen IT: Large-scale comparative genomic analyses of cytoplasmic membrane transport systems in prokaryotes. J Mol Microbiol Biotechnol 2007;12:165-179.

Rendulic S, Jagtap P, Rosinus A, Eppinger M, Baar C, Lanz C, Keller H, Lambert C, Evans KJ, Goesmann A, Meyer F, Sockett RE, Schuster SC: A predator unmasked: life cycle of Bdellovibrio bacteriovorus from a genomic perspective. Science 2004;303:689-692.

Robinson LS, Ashman EM, Hultgren SJ, Chapman MR: Secretion of curli fibre subunits is mediated by the outer membrane-localized CsgG protein. Mol Microbiol 2006;59:870-881.

Rodionov DA, Hebbeln P, Eudes A, ter Beek J, Rodionova IA, Erkens GB, Slotboom DJ, Gelfand MS, Osterman AL, Hanson AD, Eitinger T: A novel class of modular transporters for vitamins in prokaryotes. J Bacteriol 2009;191: $42-51$.
Rossier O, Starkenburg SR, Cianciotto NP: Legionella pneumophila type II protein secretion promotes virulence in the $\mathrm{a} / \mathrm{j}$ mouse model of Legionnaires' disease pneumonia. Infect Immun 2004;72:310-321.

Rudnick G, Kramer R, Blakely RD, Murphy DL, Verrey F: The SLC6 transporters: perspectives on structure, functions, regulation, and models for transporter dysfunction. Pflugers Arch 2014;466:25-42.

Sachelaru I, Petriman NA, Kudva R, Kuhn P, Welte T, Knapp B, Drepper F, Warscheid B, Koch HG: YidC occupies the lateral gate of the SecYEG translocon and is sequentially displaced by a nascent membrane protein. J Biol Chem 2013;288:16295-16307.

Saier MH Jr: Active transport in communication, protection and nutrition. J Mol Microbiol Biotechnol 2007;12:161-164.

Saier MH Jr, Reddy BL: Holins in bacteria, eukaryotes, and archaea: multifunctional xenologues with potential biotechnological and biomedical applications. J Bacteriol 2015; 197:7-17.

Saier MH Jr, Reddy VS, Tsu BV, Ahmed MS, Li C, Moreno-Hagelsieb G: The Transporter Classification Database (TCDB): recent advances. Nucleic Acids Res 2016;44:D372-D379.

Sato M, Sinha PK, Torres-Bacete J, Matsuno-Yagi A, Yagi T: Energy transducing roles of antiporter-like subunits in Escherichia coli $\mathrm{NDH}$ 1 with main focus on subunit NuoN (ND2). J Biol Chem 2013;288:24705-24716.

Saurin W, Hofnung M, Dassa E: Getting in or out: early segregation between importers and exporters in the evolution of ATP-binding cassette (ABC) transporters. J Mol Evol 1999;48: 22-41.

Sharma-Kuinkel BK, Mann EE, Ahn JS, Kuechenmeister LJ, Dunman PM, Bayles KW: The Staphylococcus aureus lytsr two-component regulatory system affects biofilm formation. J Bacteriol 2009;191:4767-4775.

Sharom FJ: Flipping and flopping - lipids on the move. IUBMB Life 2011;63:736-746.

Shrivastava R, Jiang X, Chng SS: Outer membrane lipid homeostasis via retrograde phospholipid transport in Escherichia coli. Mol Microbiol 2017;106:395-408.

Sinha S, Ambur OH, Langford PR, Tonjum T, Kroll JS: Reduced DNA binding and uptake in the absence of Dsba1 and Dsba2 of Neisseria meningitidis due to inefficient folding of the outer-membrane secretin PilQ. Microbiology 2008;154:217-225.

Sockett RE: Predatory lifestyle of Bdellovibrio bacteriovorus. Annu Rev Microbiol 2009;63:523539

Su CC, Bolla JR, Kumar N, Radhakrishnan A, Long F, Delmar JA, Chou TH, Rajashankar KR, Shafer WM, Yu EW: Structure and function of Neisseria gonorrhoeae MtrF illuminates a class of antimetabolite efflux pumps. Cell Rep 2015;11:61-70. 
Takeda H, Hattori M, Nishizawa T, Yamashita K, Shah ST, Caffrey M, Maturana AD, Ishitani R, Nureki O: Structural basis for ion selectivity revealed by high-resolution crystal structure of $\mathrm{Mg}^{2+}$ channel MgtE. Nat Commun 2014;5: 5374.

Tamang DG, Rabus R, Barabote RD, Saier MH Jr: Comprehensive analyses of transport proteins encoded within the genome of "Aromatoleum aromaticum" strain EbN1. J Membr Biol 2009;229:53-90.

Tang S, Chia GH, Lee HK: Magnetic core-shell iron(II,III) oxide@layered double oxide microspheres for removal of 2,5-dihydroxybenzoic acid from aqueous solutions. J Colloid Interface Sci 2015;437:316-323.

Van Rosmalen M, Saier MH Jr: Structural and evolutionary relationships between two families of bacterial extracytoplasmic chaperone proteins which function cooperatively in fimbrial assembly. Res Microbiol 1993;144:507527.

Varon M, Fine M, Stein A: Effect of polyamines on the intraperiplasmic growth of Bdellovibrio at low cell densities. Arch Microbiol 1983;136:158-159.

Vitreschak AG, Rodionov DA, Mironov AA, Gelfand MS: Regulation of riboflavin biosynthesis and transport genes in bacteria by transcriptional and translational attenuation. $\mathrm{Nu}-$ cleic Acids Res 2002;30:3141-3151.

Waksman G, Hultgren SJ: Structural biology of the chaperone-usher pathway of pilus biogenesis. Nat Rev Microbiol 2009;7:765-774.
Wang B, Dukarevich M, Sun EI, Yen MR, Saier MH Jr: Membrane porters of ATP-binding cassette transport systems are polyphyletic. J Membr Biol 2009;231:1-10.

Wickles S, Singharoy A, Andreani J, Seemayer S, Bischoff L, Berninghausen $\mathrm{O}$, Soeding J, Schulten K, van der Sluis EO, Beckmann R: A structural model of the active ribosomebound membrane protein insertase YidC. Elife 2014;3:e03035.

Wortham BW, Patel CN, Oliveira MA: Polyamines in bacteria: pleiotropic effects yet specific mechanisms. Adv Exp Med Biol 2007; 603:106-115.

Wu SS, Wu J, Cheng YL, Kaiser D: The pilH gene encodes an $\mathrm{ABC}$ transporter homologue required for type iv pilus biogenesis and social gliding motility in Myxococcus xanthus. Mol Microbiol 1998;29:1249-1261.

Wu SS, Wu J, Kaiser D: The Myxococcus xanthus pilT locus is required for social gliding motility although pili are still produced. Mol Microbiol 1997;23:109-121.

Yang T, Liu Q, Kloss B, Bruni R, Kalathur RC, Guo Y, Kloppmann E, Rost B, Colecraft HM, Hendrickson WA: Structure and selectivity in bestrophin ion channels. Science 2014;346: 355-359.
Yang Y, Jin H, Chen Y, Lin W, Wang C, Chen Z, Han N, Bian H, Zhu M, Wang J: A chloroplast envelope membrane protein containing a putative $\operatorname{LrgB}$ domain related to the control of bacterial death and lysis is required for chloroplast development in Arabidopsis thaliana. New Phytol 2012;193:81-95.

Zakataeva NP, Kutukova EA, Gronskii SV, Troshin PV, Livshits VA, Aleshin VV: Export of metabolites by the proteins of the DMT and RhtB families and its possible role in intercellular communication (in Russian). Mikrobiologiia 2006;75:509-520.

Zhai Y, Saier MH Jr: A web-based program (WHAT) for the simultaneous prediction of hydropathy, amphipathicity, secondary structure and transmembrane topology for a single protein sequence. J Mol Microbiol Biotechnol 2001;3:501-502.

Zhai YF, Heijne W, Saier MH Jr: Molecular modeling of the bacterial outer membrane receptor energizer, ExbBD/TonB, based on homology with the flagellar motor, MotAB. Biochim Biophys Acta 2003;1614:201-210.

Zheng WH, Västermark A, Shlykov MA, Reddy V, Sun EI, Saier MH Jr: Evolutionary relationships of ATP-binding cassette $(\mathrm{ABC})$ uptake porters. BMC Microbiol 2013;13:98.

Zhou J, Wang K, Xu S, Wu J, Liu P, Du G, Li J, Chen J: Identification of membrane proteins associated with phenylpropanoid tolerance and transport in Escherichia coli BL21. J Proteomics 2015;113:15-28. 